\title{
Porto, Marcelo F., Tania Pacheco, Jean P. Leroy (eds.) Injustiça Ambiental e Saúde no Brasil: o Mapa de Conflitos. Rio de Janeiro: Editora Fiocruz, 2013. 306p.
}

Ana Carolina Dionísio

Universidade Federal de Santa Catarina

carudionisio@gmail.com

Florianópolis

Brasil

Com o título nada imparcial de "A farra da antropologia oportunista", a matéria da revista Veja de 5 de maio de 2010 esbanja virulência ao questionar os "Critérios frouxos para a delimitação de reservas indígenas e quilombos" que só serviriam para "engordar as contas de organizações não governamentais" e, pior, "diminuem ainda mais o território destinado aos brasileiros que querem produzir". Para sustentar sua tese, os repórteres apresentam oito casos de conflitos envolvendo a demarcação de terras indígenas, quilombolas e de comunidades tradicionais, cujas populações e suas respectivas demandas são retratadas ora como obstáculos ao desenvolvimento econômico, ora como peças do jogo da "indústria das demarcações", supostamente formada por antropólogos, ativistas e religiosos "associados" a agentes públicos e organizações não-governamentais ligados a "uma esquerda que ainda insiste em extinguir o capitalismo, imobilizando terras para a produção".

Assim como as oito histórias apresentadas na reportagem integram um universo bem mais amplo de conflitos, o discurso da revista faz parte de um caldo ideológico que alimenta e é alimentado não só por alguns setores da imprensa, mas também pelo senso comum e tribunas do Legislativo. Temperado com doses fortes de racismo, este caldo tem como um dos seus principais ingredientes o imperativo do progresso, que embasa uma noção de desenvolvimento econômico capaz de justificar violências e expropriações impingidas a diversas populações cujos modos de vida são incompatíveis com estes princípios. Um dos principais fatores de tal incompatibilidade é a relação destas populações com o meioambiente, que permeia, por sua vez, suas lógicas de trabalho e produção, além de suas noções do que seja qualidade de vida. Enquanto no discurso hegemônico veiculado por Veja os recursos naturais representam "vastidões férteis e inexploradas" que "garantiriam a ampliação do agronegócio e do peso da nação no comércio mundial", para os povos originários e comunidades tradicionais estes garantem a sobrevivência a longo prazo não apenas das pessoas, mas de complexos agroalimentares e bioculturais fundamentais para a sustentabilidade ambiental do país - talvez até do planeta.

Dar visibilidade a estas populações e suas respectivas vulnerabilidades socioambientais é o objetivo do Mapa de Conflitos Envolvendo Injustiça Ambiental e Saúde no Brasil, cujos dados são analisados criticamente no livro Injustiça Ambiental e Saúde no Brasil: o Mapa de Conflitos, organizado por Marcelo Firpo Porto, Tania Pacheco e Jean Pierre Leroy, lançado em 2013. O Mapa que deu origem ao livro é resultado do trabalho de

\footnotetext{
${ }_{1}^{1}$ Disponível em http://veja.abril.com.br/050510/farra-antropologia-oportunista-p-154.shtml, Acesso em 19 ago. 2014.
} 
uma equipe multidisciplinar ligada à Rede Brasileira de Justiça Ambiental (RBJA), que inclui cientistas sociais, profissionais das áreas de humanas e exatas, um missionário, um economista e uma jornalista e desde 2002 vem se consolidando como "um espaço de identificação, solidarização e fortalecimento dos princípios de justiça ambiental" (Porto; Pacheco; Leroy 2013, 18). Através da compilação de um Banco Temático construído pela Fundação Oswaldo Cruz (Fiocruz) e pela Federação de Órgãos para Assistência Social e Educacional (Fase) para reunir documentos referentes aos anos 2002 e 2009, além da abertura de um formulário virtual em 2008 para a coleta de dados, foram levantadas e sistematizadas 297 denúncias de casos de injustiça ambiental ocorridos a partir de 2006. Todos estes dados foram lançados num portal de internet em 2010 (http://www.conflitoambiental.icict.fiocruz.br/); de lá até 2012 outros quase quatrocentos casos foram registrados através desta ferramenta.

Longe de significar uma solução para estes conflitos, a projeção pública deles pode auxiliar na proteção destas populações, ao escancarar não só as violências das quais são vítimas, mas também sua mobilização e articulação para combatê-las, defendendo sua autodeterminação e o direito aos seus territórios e à manutenção de seus modos de vida e costumes. Priorizando a visão e a voz dos atingidos, que frequentemente têm pouco ou nenhum espaço nos meios de comunicação e em outras esferas públicas, o Mapa demonstra-se também como um instrumento a favor da democracia, permitindo a cobrança o e monitoramento de ações governamentais. Trabalhando com uma concepção ampliada de saúde, considerando também tratos culturais e aspectos de qualidade de vida das populações mais do que simplesmente a dimensão biomédica dos impactos ambientais, o Mapa conecta a questão da saúde à discussão sobre justiça ambiental e sustentabilidade, servindo como subsídio para a construção de políticas públicas do setor que levem em conta as especificidades sócio-culturais e regionais dos atendidos.

Composto por oito ensaios, ' o livro poderia ser dividido em três partes. Na primeira, com os capítulos 1 e 2, é apresentada uma sistematização da metodologia de construção e dos resultados do Mapa, além dos conceitos que o embasam, como o de injustiça ambiental e racismo ambiental. Na segunda parte, que abarca do capítulo 3 ao 6 , os conflitos são discutidos a partir de quatro eixos temáticos: territórios de povos indígenas e comunidades tradicionais, impactos do agronegócio químico-dependente e problemáticas sócio-ambientais urbanas, além de conflitos envolvendo projetos de mineração e siderurgia e as estratégias de geração de energia. Os dois capítulos finais trazem reflexões sobre perspectivas de continuidade das dinâmicas de construção do mapa, ressaltando sua faceta de espaço de cidadania.

Como pano de fundo, a obra apresenta uma crítica ao mesmo pressuposto expresso por Veja de desenvolvimento econômico a qualquer custo (especialmente sócio-ambiental) que busca invisibilizar e deslegitimar os direitos dos atingidos em detrimento dos interesses de curto prazo de grupos poderosos justificados pela égide do progresso, da geração de empregos, de renda e de energia e do aumento das exportações. Neste sentido, chama a atenção para a responsabilidade do Estado na geração e falta de mediação nestes conflitos. Fundamentando esses questionamentos estão as noções de injustiça ambiental referente ao "mecanismo pelo qual sociedades desiguais, do ponto de vista econômico e social, destinam a maior carga dos danos ambientais do desenvolvimento às populações de baixa renda", (Idem, 119), grupos etnicamente discriminados, comunidades tradicionais e populações marginalizadas e vulneráveis - e de racismo ambiental, que valoriza o componente étnico-racial, além do socioeconômico, na análise dos conflitos, que em grande parte têm comunidades indígenas, quilombolas e "não-brancas", historicamente 
excluídas de processos decisórios no Brasil, como protagonistas desfavorecidos. À luta ambiental alia-se, então, o combate ao racismo.

Quase dois terços dos conflitos registrados no mapa abarcam povos indígenas e comunidades tradicionais, que incluem ribeirinhos, pescadores artesanais e extrativistas. Uma leitura sobre este quadro é trazida na capítulo 3, Povos indígenas e comunidades tradicionais: os visados territórios dos invisíveis. Na base destes conflitos está a diferença entre atingidos e agressores na sua relação com o meio-ambiente e na sua concepção de qualidade de vida. Esta distinção materializa-se não só num uso intensivo dos recursos naturais que se contrapõe ao seu aproveitamento sustentável, mas à disputa pelos territórios destes sujeitos "invisíveis", cujas demandas e agressões sofridas - que incluem ameaças, assassinatos, contaminação da água e dos solos por agrotóxicos e perda da biodiversidade - dificilmente emergem como ponto de pauta na opinião pública. Quando isto acontece, não é raro que suas reivindicações sejam hostilizadas, tanto pelo senso comum quanto em textos pretensamente informativos, como neste trecho da matéria da revista Veja supracitada, intitulado "Índio bom é índio pobre":

Em 2000, cinquenta famílias de guaranis se mudaram para uma praia em Peruíbe, no Litoral Sul de São Paulo. A terra que eles ocuparam é infértil, mas ainda assim poderiam ter feito um ótimo negócio. O empresário Eike Batista queria construir um porto no local e ofereceu aos índios uma fazenda produtiva, com infraestrutura, dois rios, um pesque-pague e até caça. Mais: daria 1 milhão de reais a cada família. A tribo tirou a sorte grande - ou quase. A Funai barrou o acordo em 2007. Alegou que os sete anos de ocupação irregular da área converteram os índios em moradores tradicionais do local. A chefe Lílian Gomes (em pé, ao fundo) lamentou. Moradora da região desde 2002, ela é casada com um caminhoneiro (branco), tem carro, TV, computador, faz compras no supermercado e não conseguiu impedir a Funai de enterrar a melhor oportunidade de ascensão social que seus liderados tiveram.

Mesclando um discurso falacioso e racista com um exercício de reportagem pobre, este curto excerto verbaliza cabalmente a interpretação hegemônica sobre os conflitos. O caso tratado é o da aldeia Piaçaguera, onde, em 2006, o empresário Eike Batista pretendia instalar um porto. Ignorando os procedimentos legais de licenciamento ambiental, o grupo empreendedor e o Conselho Estadual do Meio Ambiente convocaram uma audiência pública em 2008 para apresentar o projeto e (supostamente) seus impactos. Ao contrário do que Veja afirma, quem barrou o "acordo" (na verdade, uma proposta unilateral) não foi a Funai, mas o juiz Antônio André Muniz Mascarenhas de Souza, quem, a pedido do Ministério Público, cancelou a realização da audiência. Isso porque Piaçaguera já fora declarada pela Funai como Terra Indígena em 2002 e estava em fase final de demarcação, "razão pela qual nenhum empreendimento poderá ser implantado no local até sua conclusão"2. A matéria, contudo, desqualifica a tradicionalidade da ocupação do local, caracterizando-a como uma criação da Funai que trava um megaempreendimento e enterra "a melhor oportunidade de ascensão social" que a população teria, numa manobra ideológica em que os imperativos do capitalismo de mercado valem mais do que a sustentabilidade de modos de vida e das relações interdependentes destes com o meioambiente, problemática comum a vários outros conflitos apresentados no Mapa. Além disso, insinua um questionamento à etnicidade da professora e cacique Lilian Gomes, por ela ser casada com um não-indígena e possuir "carro, TV, computador, faz compras no

\footnotetext{
${ }^{2}$ Conforme informações do próprio MAPA, disponiveìis em

http://www.conflitoambiental.icict.fiocruz.br/index.php?pag=ficha\&cod=242, Acesso em 24 nov. 2015.
} 
supermercado", não preenchendo assim um modelo folclorizado e pré-conceituado do que é ser indígena.

Além deste tipo de violência simbólica, a história da TI Piaçaguera também é emblemática pelos atores e relações de forças postas em jogo. A aliança entre órgãos governamentais e iniciativa privada para a instalação de mega-empreendimentos que afetam profundamente, e até desestruturam, povos e comunidades tradicionais inteiros é comum em 52\% dos casos levantados no Mapa (Pacheco; Porto; Rocha 2013, 56), colocando o Estado brasileiro como um dos principais agentes de injustiças ambientais na atualidade, o que inclui também a conivência do poder público e entidades governamentais nos processos de licenciamento ambiental viciados e a omissão destes na proteção dos interesses dos atingidos. Dentre os apoiadores destes últimos, como no caso Piaçaguera, o Ministério Público tem forte atuação em 53\% dos casos (Idem, 69).

Outros tipos de empreendimentos de infra-estrutura, como barragens e hidrelétricas, usinas nucleares e termoelétricas, hidrovias, rodovias, gasodutos, refinarias de petróleo e gás, além de projetos de mineração e siderurgia, respondem por mais de $50 \%$ das atividades geradoras de injustiças ambientais, de acordo com o levantamento do Mapa, causando, em grande parte dos casos, a "alteração no regime tradicional de uso e ocupação do território" (Idem, 62), especialmente nas áreas rurais e de florestas. Desta maneira, embora $84 \%$ da população brasileira viva atualmente em cidades, os conflitos que atingem populações do campo, florestas e zonas costeiras respondem por $60 \%$ dos casos registrados. Este fato deve-se, de acordo com a obra, à dependência da exploração dos recursos naturais que caracteriza a expansão capitalista brasileira.

Neste sentido, o agronegócio químico-dependente, monocultor e voltado à produção de commodities para exportação também ganha destaque no cenário de injustiças ambientais, abarcando sozinho 33\% das denúncias (Porto 2013, 134), conforme vemos no capítulo 4 do livro, Injustiça Ambiental no Campo e nas Cidades: do Agronegócio químicodependente às zonas de sacrifício urbanas. Se considerarmos também a pecuária e a produção de camarões e celulose, esta proporção aumenta significativamente. Além da expropriação e concentração fundiárias, outros possíveis impactos causados por estas atividades são violência e impunidade no campo; exploração de mão de obra; diminuição da biodiversidade e, consequentemente, da segurança e soberania alimentares; além de uma preocupação crescente no Brasil: a contaminação do meio-ambiente, dos trabalhadores e trabalhadoras rurais e dos consumidores pelo uso indiscriminado de agrotóxicos. Se por um lado encabeçamos o ranking mundial de produção de soja, por exemplo, por outro lideramos também a lista de maiores consumidores mundiais de agrotóxicos, conseqüência direta da expansão da Revolução Verde na América Latina, especialmente a partir da década de 1950.

Alimentando o êxodo rural, a expansão monocultora do agronegócio repercute negativamente não só no campo, mas também no urbano, em que o crescimento desordenado das periferias é apenas um destes reflexos. Estas áreas desfavorecidas e marginalizadas acabam concentrando vários riscos ambientais, seja por estarem suscetíveis a desastres como inundações e deslizamentos, pela falta de infra-estrutura básica ou por serem alvo de especulação imobiliária. Seguindo a lógica do racismo e da injustiça ambiental, estas áreas são comumente preferidas para a instalação de aterros e lixões e de indústrias poluentes e perigosas, reflexão trazida também neste quarto capítulo do livro.

No campo ou nas cidades, nas florestas ou zonas costeiras, em comunidades indígenas, quilombolas, caiçaras, extrativistas, ribeirinhas ou nos bairros das margens urbanas, os atingidos por injustiças e racismo ambientais não aceitam passivamente as 
agressões, o que pode ser compreendido na parte final do livro. São inúmeros os movimentos e iniciativas de articulação, resistência e busca de alternativas futuras para a preservação sustentável dos modos de vida, arranjos produtivos, ecossistemas, práticas culturais e costumes relacionados a estas populações, sendo uma delas o Mapa. Seu caráter participativo e aberto para qualquer cidadão ou cidadã apresentar sua denúncia e consultar as correntes, aumenta seu potencial de democratização de informações. A compilação da obra Injustiça Ambiental e Saúde no Brasil fortalece este eixo, trazendo não apenas dados estatísticos, mas uma leitura dos fatos comprometida e engajada com os interesses das populações atingidas, fundamental para a transformação social necessária à superação de desigualdades, injustiças e racismos, não só ambientais. Enquanto estes existirem e continuarem sendo justificadas pelo "progresso", o Mapa estará inconcluso, assim como o livro. Ao abordar conflitos envolvendo uma rede enorme e dinâmica de atores com pesos socioeconômico, cultural e político diferentes, Injustiça Ambiental e Saúde no Brasil será sempre passível de re-análises, reconfigurações e reescritas. Novos conflitos podem surgir, bem como disputas atuais podem passar por mudanças de rumos ou intensificações de tensões. O caráter de permanente construção da obra não diminui, contudo, sua relevância política e acadêmica para a promoção da sustentabilidade socioambiental e da democracia e para o questionamento de discursos racistas, excludentes e preconceituosos. 